\title{
Contribuições da Análise Ambiental para a Elaboração do Plano De Desenvolvimento de Assentamento (PDA)
}

\section{Contribuitions of Environmental Analysis to the Preparation of the Settlement Development Plan(SDP)}

Tasso Ivo de Oliveira Neto ${ }^{13}$, Vládia Pinto Vidal de Oliveira ${ }^{14}$

DOI: https://doi.org/10.52719/bjas.v3i1.3953

\begin{abstract}
RESUMO
O Plano de Desenvolvimento de Assentamento (PDA) é parte do Programa de Políticas Públicas, Agrícola e Fundiária e da Reforma Agrária no Brasil, e tem como finalidade subsidiar uma proposta de desenvolvimento sustentável para os assentamentos que serão criados, orientando diversas diretrizes e normas técnicas para a sua implantação e respectivos investimentos. Exigem-se dos profissionais envolvidos conhecimentos técnicos especializados em: planejamento, economia, administração rural, meio ambiente, sociologia rural. A primeira etapa do PDA compreende o diagnóstico ambiental, isto é, refere-se à análise das condições geoambientais e socioeconômicas. Deste modo, este artigo tem como objetivo fomentar a análise ambiental no diagnóstico do meio natural na elaboração de PDA. Para tanto, realizouse o diagnóstico ambiental do Assentamento Angicos II (Tauá - Ceará, Brasil). Os procedimentos teórico-metodológicos estão pautados nos preceitos da análise ambiental e adota a concepção metodológica de estudos sistêmicos. O trabalho aponta que a análise ambiental facilitou o diagnóstico ambiental do PDA, não apresentando dificuldades na compreensão do meio natural. Os resultados demonstraram que a análise ambiental contribui significativamente na interpretação dos dados para a elaboração do PDA. A análise geossistêmica, por meio da integração dos seus elementos, proporcionou perceber as condições ambientais, além de apreender o comportamento dos agentes que compõem o objeto estudado e dos sistemas ambientais.
\end{abstract}

Palavras-chave: Assentamento Rural. Meio Natural. Planejamento.

\begin{abstract}
The Settlement Development Plan (PDA) is part of the Public Agricultural and Land Policy and Agrarian Reform Program in Brazil and aims to support a sustainable development proposal for the settlements that will be created, guiding several guidelines and technical standards for the its implementation and the respective investments and requiring specialized technical knowledge from the professionals involved, such as planning, economics, rural administration, environment, rural sociology. The first stage of the PDA comprises the environmental

\footnotetext{
${ }^{13}$ Doutorando do Programa de Pós-Graduação em Geografia da Universidade Federal do Ceará PPGGeo/UFC, Fortaleza-CE, tassoivo@gmail.com.

${ }^{14}$ Professora Doutora do Programa de Pós-Graduação em Geografia da Universidade Federal do Ceará - PPGGeo/UFC, Fortaleza-CE, vladia.ufc@gmail.com.
} 
diagnosis, that is, refers to the analysis of the geoenvironmental and socioeconomic and socioeconomic aspects. Thus, this article aims to promote environmental analysis in the diagnosis of the natural environment in the development of PDA. To this end, the environmental diagnosis of the Angicos II Settlement (Tauá - Ceará - Brazil) was carried out. Theoreticalmethodological procedures are based on the precepts of environmental analysis, adopting the methodological conception of systemic and holistic studies. The study points out that the environmental analysis facilitated the environmental diagnosis of the PDA, presenting no difficulties in understanding the natural environment. The results demonstrate the environmental analysis contributes significantly in the interpretation of the data for the elaboration of the PDA. The geosystemic study through the integration allowed to perceive the environmental conditions, besides apprehending the behavior of the agents that compose the object studied and the sustainability of the environmental systems.

Keywords: Rural settlement. Natural Environment. Planning.

\section{INTRODUÇÃO}

O PDA é parte do Programa de Políticas Públicas, Agrícola e Fundiária e da Reforma Agrária no Brasil e tem como finalidade subsidiar uma proposta de desenvolvimento sustentável para os assentamentos que serão criados. Enquanto instrumento de política pública, constitui uma ação estruturante nos processos de instalação de assentamentos rurais, estabelecendo os procedimentos para a execução de políticas sobre moradia e produção (Miranda \& Cunha, 2018).

A instrução normativa $\mathrm{N}^{\circ}$ 15, de 30 de março de 2004 do Instituto Nacional de Colonização e Reforma Agrária (INCRA), que dispoe sobre o processo de implantação e desenvolvimento de projetos de assentamento de reforma agrária, traz o Plano de Desenvolvimento do Assentamento como ação necessária, que promove a exploração racional e sustentável da área e a melhoria de qualidade de vida dos assentados. Apesar de revogada, a Resolução No 387, de 27 de dezembro de $2006^{15}$, do Conselho Nacional do Meio Ambiente (CONAMA), traz o marco conceitual do PDA como plano que reúne

os elementos essenciais para o desenvolvimento dos Projetos de Assentamento de Reforma Agrária, em estrita observância à diversidade de casos compreendida pelos diferentes biomas existentes, com destaque para seus aspectos fisiográficos, sociais, econômicos, culturais e ambientais, sendo instrumento básico para a formulação de projetos técnicos e todas as atividades a serem planejadas e executadas nas áreas de assentamento, constituindo-se numa peça fundamental ao monitoramento e avaliação dessas ações (Brasil, 2006, p. 02)

Este plano orientará diversas diretrizes e normas técnicas para a sua implantação e os respectivos investimentos. O PDA é predominantemente um trabalho intelectual de grande

${ }^{15}$ Esta lei foi revogada pela Resolução CONAMA № 458 DE 16/07/2013. 

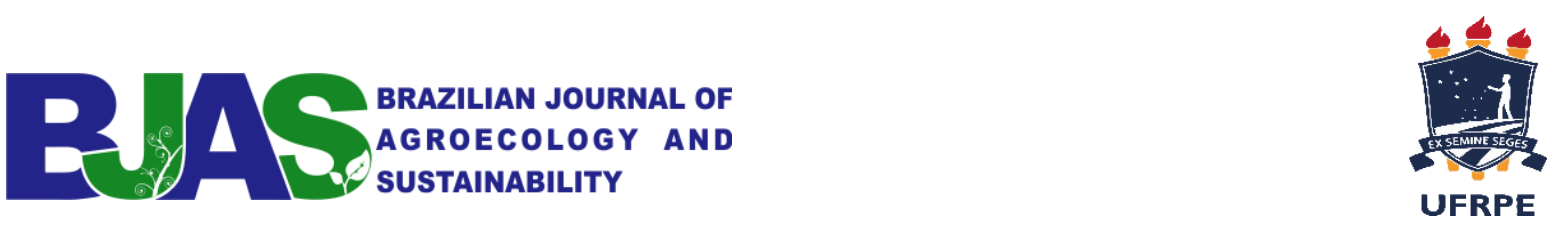

complexidade, exigindo dos profissionais envolvidos conhecimentos técnicos especializados, como, por exemplo, em planejamento, economia, administração rural, meio ambiente, sociologia rural e etc. (Brasil, 1993).

Segundo Freitas et al. (2018) o processo de parcelamento do assentamento é orientado pelas informações do meio físico, uso e ocupação da área geradas na etapa de desapropriação complementadas pelas informações produzidas na etapa posterior de elaboração do Plano de Desenvolvimento de Assentamento (PDA). Corroborando com o referido autore, Wickert, et al. (2000 apud SILVA, 2011), uma das etapas do PDA é o diagnóstico ambiental, que refere-se às análises temáticas que são conduzidas através do relacionamento sistêmico, holístico e dialético entre os componentes naturais. No que concerne à abordagem dos estudos integrados, consideram-se: o ecossistema e o geossistema. O ecossistema é definido como

qualquer unidade que inclui todos os organismos (comunidade biótica) em uma dada área interagindo com o ambiente físico, de modo que um fluxo de energia leve as estruturas bióticas claramente definidas e a ciclagem de materiais entre os componentes vivos e não vivos (Odum \& Barret, 2007, p.18).

De acordo com estes autores, são considerados três tipos de ecossistemas: os ecossistemas naturais e os agroecossistemas. Os ecossistemas naturais referem-se à primeira unidade ecológica, composta pelos organismos vivos (biótico) e seu ambiente não vivo (abiótico), que se inter-relacionam e interagem uns com os outros. Os agroecossistemas são sistemas naturais com forte interferência humana e diferem por três maneiras: I. Energia auxiliar, em que a energia é aumentada ou subsidiada pelo controle (trabalho) humano; II. Diversidade, que é reduzida a fim de aumentar a produção de alimentos; e III. Seleção artificial, em que são dominantes organismos oriundos da seleção artificial, isto é, são unidades de sistemas produtivos (Odum \& Barret, 2007).

Segundo Souza e Oliveira (2011), o geossistema remete a um sistema geográfico natural ligado a um território e deriva das relações mútuas entre os componentes do potencial ecológico e da exploração biológica, e destes com a ação antrópica. Dessa maneira, o geossistema ou sistema ambiental enfatiza as inter-relações horizontais, isto é, a produção geográfico-espacial.

Dito isto, dentre os princípios teóricos e metodológicos para o diagnóstico ambiental, optou-se por trabalhar com a análise ambiental. Esta está balizada numa visão sistêmica pautada no geossistema, revelando, de forma sintética, as relações mútuas entre os componentes geoambientais, onde os levantamentos temáticos são fundamentais para reconhecer esta realidade, pois, nestas análises setoriais, buscam-se identificar e interpretar os diversos 

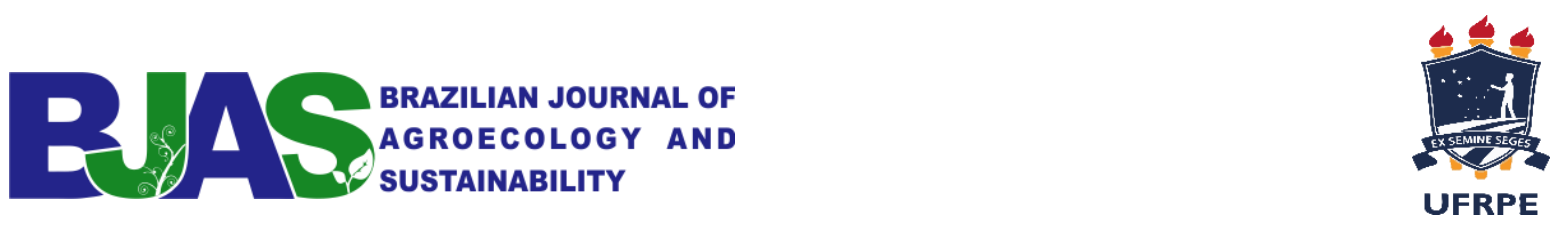

componentes geoambientais.

Este artigo tem como objetivo realizar o diagnóstico ambiental do Assentamento Angicos II (Tauá - Ceará, Brasil), visando fomentar a análise ambiental no diagnóstico do meio natural na elaboração de PDA. Ademais, acredita-se que esta pesquisa seja uma contribuição para o planejamento em assentamentos rurais. Sabe-se que esta discussão não se encerra aqui, e nem se tem a pretensão de fazê-lo. Busca-se, sobretudo, contribuir para o enriquecimento do debate acerca destes temas trabalhados ao longo do texto.

\section{METODOLOGIA}

\subsection{Caracterização da área de estudo}

O assentamento está inserida no município de Tauá, situado a sudoeste do Estado do Ceará, mais precisamente na microrregião do Sertão dos Inhamuns, distando $320 \mathrm{~km}$ da capital Fortaleza. O Projeto de Assentamento Angicos II (Figura 01) foi criado em 1997 e localiza-se no distrito de Tauá, distante $18 \mathrm{~km}$ da sede municipal, e seu acesso se dá pela CE-176, asfaltada, que liga Tauá a Arneiroz. Depois de percorridos $11 \mathrm{~km}$, faz-se uma conversão à esquerda, seguindo numa estrada carroçável por aproximadamente $8 \mathrm{~km}$ até o assentamento.

No tocante aos aspectos ambientais, a área está inserida no sub-sistema ambiental dos Sertões Meridionais dos Inhamuns, abrangendo mais de $13.500 \mathrm{~km}^{2}$. Este sistema faz parte dos sistemas ambientais dos Sertões Sul, que estão encravados no Domínio Natural das Depressões Sertanejas Semiáridas e Sub-úmidas (Ceará, 2009). O assentamento Angicos II, estudado durante o período de março de 2014 a março de 2016, iniciou sua ocupação por meio de um levantamento de terras do município de Tauá para fins de reforma agrária.

Esse levantamento foi realizado pelo Sindicato dos Trabalhadores e pela Comissão Pastoral da Terra, de tal modo que o processo de fundação do Projeto de Assentamento Angicos II foi consumado em 1998, após a compra junto ao proprietário da fazenda Angicos, Sebastião Rego (Alves \& Feitosa, 2002). O Angicos está dividido em duas agrovilas, Divisão e Barro Branco, distando cerca de um quilômetro uma da outra.

Conforme verificado em trabalho de campo, o número de famílias aumentou para 81, sendo 61 cadastradas e 20 agregadas $^{16}$. A grande maioria dessas famílias é oriunda do próprio município e das proximidades de Tauá. No assentamento, cada uma das 61 famílias assentadas possui uma área média de 52 hectares (38 hectares individual e 14 hectares dentro da Reserva

\footnotetext{
${ }^{16}$ Filhos que construíram suas famílias e suas casas nos lotes dos pais.
} 
Legal $^{17}$ ), perfazendo um total de 3.172 hectares (Oliveira Neto, 2016).

Figura 01

Localização do Assentamento Angicos II.

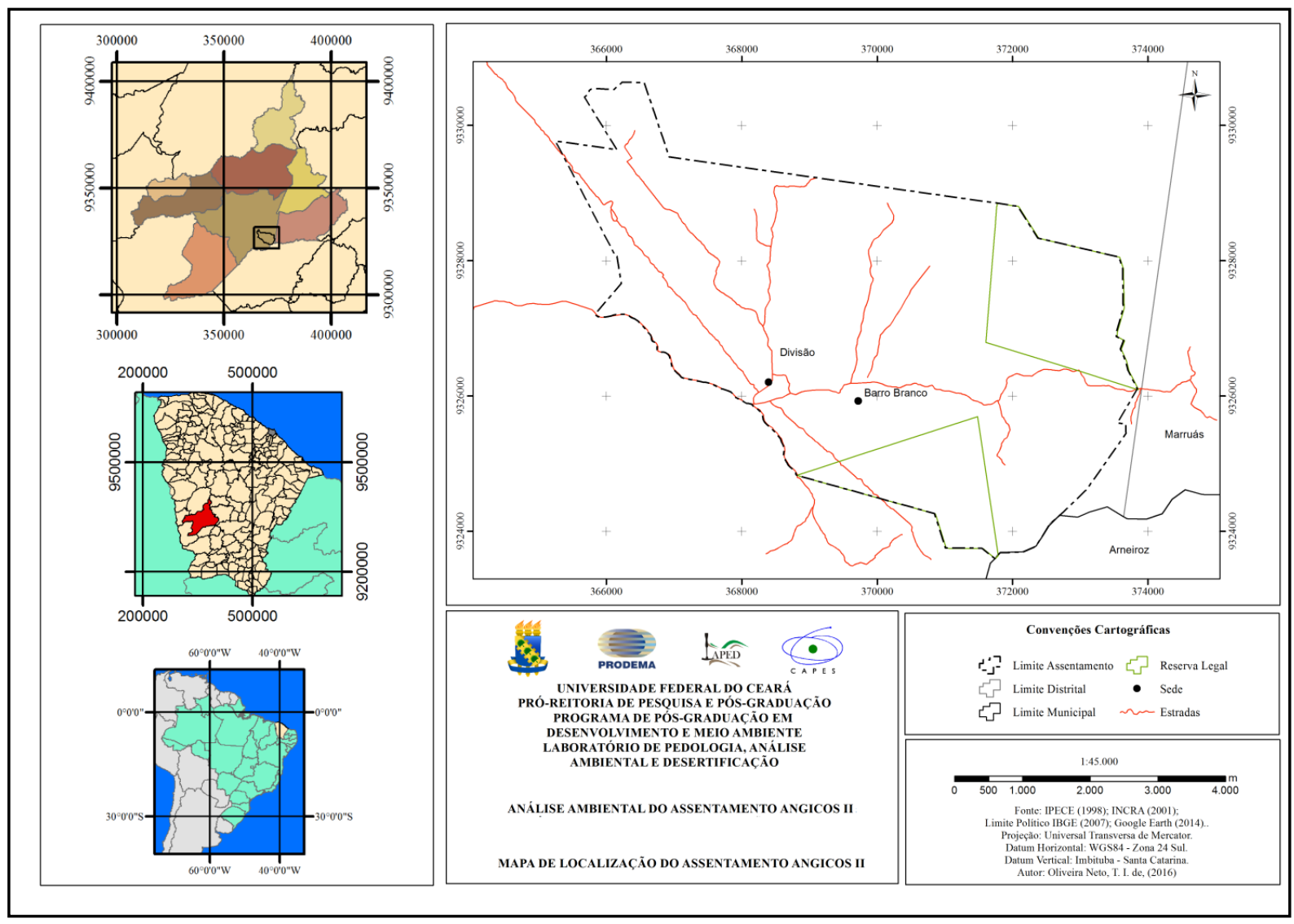

Fonte: Oliveira Neto, 2016, p. 18.

A pesquisa foi sistematizada em duas fases. A primeira tratou do levantamento de dados secundários da área de estudo, revisão bibliográfica, pesquisa documental e trabalhos de campo. Incluem-se o levantamento, a triagem e o fichamento de materiais bibliográficos pertinentes aos temas da pesquisa. As análises setoriais foram necessários para o entendimento do ambiente, sendo base para a síntese e as correlações interdisciplinares (Souza \& Oliveira, 2011). Nesta fase, foi selecionada e analisada uma cartografia básica e temática sobre a área e seu entorno, com destaque para as cartas geológicas, geomorfológicas, pedológicas, fitoecológicas e de uso e ocupação.

Na confecção dos mapas, optou-se pela utilização do Datum Horizontal SIRGAS 2000,

\footnotetext{
${ }^{17}$ A Reserva Legal refere-se à área localizada no interior de uma propriedade rural, com função de assegurar o uso econômico de modo sustentável dos recursos naturais do imóvel rural, auxiliar a conservação e a reabilitação dos processos ecológicos e promover a conservação da biodiversidade, bem como o abrigo e a proteção de fauna silvestre e da flora nativa (Brasil, 2012).
} 
que recentemente foi outorgado como oficial no Brasil. O sistema de projeção adotado foi o Universal Transvesa de Mercator (UTM). Este sistema de medida linear em metros facilita nos trabalhos de campo, sendo registrado sempre números inteiros. O Datum Vertical tem como ponto de origem o marégrafo de Imbituba (SC), estável por um longo período de observação, que estabelece a altitude zero do Brasil (Rosa, 2004).

De posse da delimitação do assentamento, arquivo Shapefile obtido através do INCRA, sucedeu-se a contextualização dos sistemas ambientais, construindo mapas setoriais em escala 1:30.000, em função do recorte espacial ser pequeno e, assim, trazer um detalhamento maior sobre as informações do área de estudo. Quanto aos equipamentos, também destacamos as imagens de satélite RapidEYE (2014) e Google Earth (2015), a utilização de receptores do Sistema de Posicionamento Global (GPS) para checagem de dados e informações, bem como o uso de softwares (ArcGIS 10, QGis 1.8, Global Mapper 11, GPS TrackMaker) para extração dessas informações e dados.

No tocante aos aspectos geológicos, utilizaram-se as bases da CPRM, mapa geológico folhas Várzea do Boi SB.24-V-D-IV (Cavalcanti, 2011) e Mombaça SB.24-V-D-V (Araújo \& Naleto, 2014) em escala 1:100.000, seguindo as suas cores padrão. Buscou-se a delimitação das unidades cronoliestratigráficas, classificando os tipos de rochas e os principais fenômenos envolvidos na história geológica regional, avaliando a disponibilidade de minerais a serem utilizados na atividade agrícola.

Para o entendimento das feições geomorfológicas, buscaram-se as bases em Souza (1988), Ceará (1997), bem como em trabalhos de campo e discussões em laboratório. Procurouse entender a compartimentação topográfica regional e a caracterização e descrição das formas de relevo de cada um dos compartimentos estudados, classificando-as para a indicação de áreas propícias à utilização e as mais restritivas ao uso, em função da maior suscetibilidade aos processos erosivos.

Para a caracterização climática da área, tomou-se dados de 01 posto de coleta da Fundação Cearense de Meteorologia e Recursos Hídricos - FUNCEME (1984 a 2014) — Posto Tauá, localizado no município de Tauá - e a temperatura média foi calculada pelo software Celina (Costa, 2007). Objetivou-se perceber o significado da importância do clima em todo o mecanismo que comanda a atividade pluvio-térmica para o conhecimento da dinâmica climática zonal, regional e local, decorrente dos padrões de circulação atmosférica e suas influências nas condições hidrológicas, como, na permanência do escoamento, e apresentar a disponibilidade de água de superfície e subterrânea.

No estudo pedológico, foi realizado o levantamento dos solos do assentamento no 

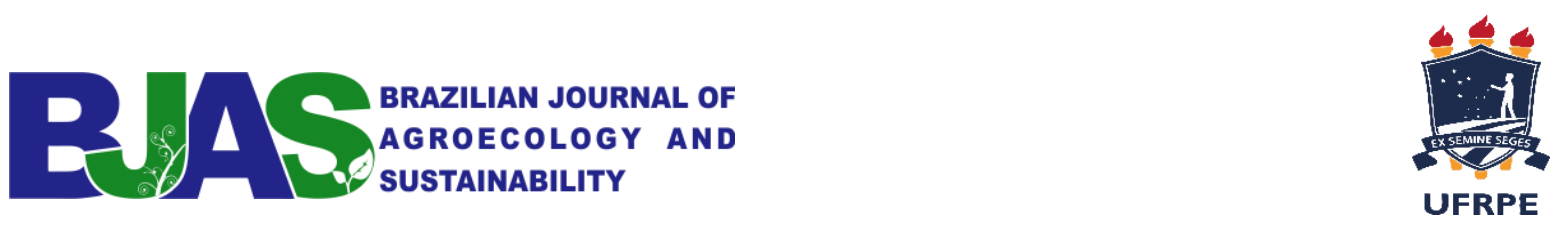

Laboratório de Pedologia, Análise Ambiental e Desertificação (LAPED), visando apresentar sua distribuição, identificando e analisando as principais características morfológicas. Determinaram-se as seguintes características: cor, textura, estrutura, porosidade, cerosidade e cimentação, segundo os procedimentos adotados pela Embrapa (2005); e avaliaram-se as características das classes de solo de acordo com suas potencialidades e limitações à utilização agrícola, baseadas em Lepsch (2011) e no mapa exploratório/reconhecimento de solos do Estado do Ceará, em escala 1:600.000 (Jacomine, Almeida \& Medeiros, 1973).

No campo da vegetação, utilizou-se o Índice de Vegetação por Diferença Normalizada. O processamento da imagem de radar do satélite LandSat 08, de dezembro de 2014, com resolução espacial de 30 metros, deu-se primeiro pela calibração dos valores de radiância; depois, pela obtenção da reflectância; e, por fim, o computo do NDVI (Ponzoni, Shimabukuro $\&$ Kuplich, 2012). Conforme estes autores, os valores muito próximos a -1 correspondem à superfície não vegetada, e, quanto mais próximo de 1, mais densa é a vegetação. Com isso, buscou-se identificar o estado de conservação ou de degradação da vegetação.

A segunda fase referiu-se à parte de interpretação, integração e análise dos resultados obtidos. O estudo integrado do ambiente ou análise ambiental adota a concepção metodológica de análises sistêmicas e holísticas (Souza, 2000; 2007; Souza, Oliveira \& Granjeiro, 2002; Souza et al., 2009; Souza \& Oliveira, 2011; Oliveira Neto, 2016). Para a delimitação dos sistemas ambientais, tomaram-se as unidades geomorfológicas como elemento de importância fundamental para o planejamento, visto que os limites do relevo e as feições do modelado são passíveis de uma delimitação mais precisa.

Ademais, foram considerados os fatores geológicos, geomorfológicos, hidroclimáticos, fitoecológicos e de uso e ocupação, pois se fazem necessários no estudo integrado dos sistemas ambientais, já que tal instrução revela uma abordagem sintética por meio das relações mútuas entre os componentes ambientais. Também realizaram-se quatro visitas de campo da área de pesquisa, munidas de esboços de mapas temáticos, auxiliadas por aparelho GPS, câmera fotográfica, altímetro, fichas de campo para caracterização morfológica do solo e análise ambiental, buscando a caracterização e o entendimento do meio físico.

\section{RESULTADOS E DISCUSSÕES}

Os sistemas ambientais não são formados pela homogeneidade fisionômica, mas por diversas paisagens em diversos estágios de evolução, ligadas umas as outras por meio de uma série dinâmica que tende ao clímax (Bertrand, 2004). Portanto, fez-se necessário o 

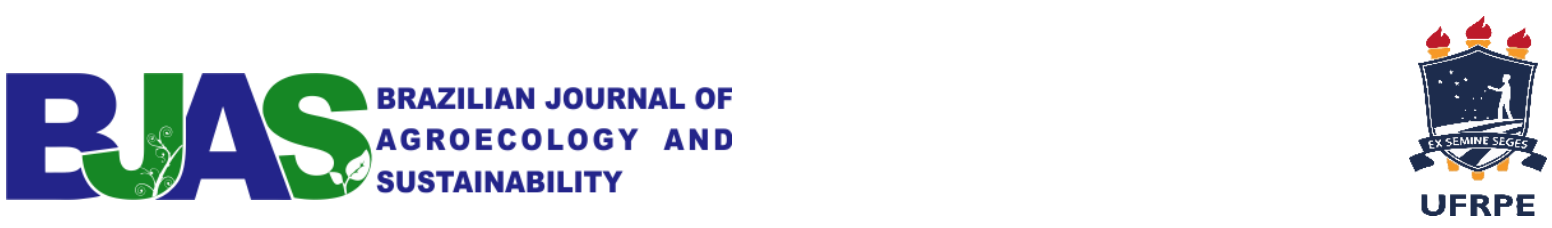

detalhamento do assentamento com base no estudo setorial, para, na sequência, buscar a análise integrada ambiental, promovida pela síntese e pelas correlações interdisciplinares. Entendendo os estudos integrados, conforme a inter-relação dos seus componentes, dimensões, características de origem, evolução e utilização, foi possível identificar as potencialidades e a limitação e, assim, avaliar melhor a capacidade de suporte ao uso e ocupação do assentamento (Souza et al., 2009; Souza \& Oliveira, 2011).

Entende-se que além das caracterísitcas ambientais, o desenvolvimento do assentamento tem forte influência da oferta e disponibilidade de serviços e da proximidade e integração com circuitos de comercialização da produção, conforme observou Santos e Castro (2019) nos assentamentos goianos. Deste modo, o PDA é uma primeira ação para estruturar as questões socioambientais e produtivas, conduzindo a melhoria de vida dos assentados. O assentamento, grosso modo, remete a terras particulares que não atingem eficiência desejada, sendo desapropriadas e destinadas à reforma agrária (Araújo et al., 2018). O estudo aponta que a análise ambiental facilitou o diagnóstico do assentamento, não apresentando grandes dificuldades na compreensão do meio natural, e, assim, torna-se uma ferramenta útil na elaboração do Plano de Desenvolvimento do Assentamento (PDA).

O Ceará tem grande parte do seu território submetido ao clima semiárido. Zanella (2007) afirma que, no caso cearense, esta complexidade se dá frente à interação dos sistemas atmosféricos, além de fatores geográficos locais e regionais. Um grande número de fatores vai influenciar as precipitações, por exemplo, quando, na estação chuvosa, que tem duração em torno de três a cinco meses, em um dia, pode chover quase todo o esperado para o mês.

A figura 02 mostra que as temperaturas médias do município de Tauá giram em torno de $25,7^{\circ} \mathrm{C}$. Para análise hidroclimática da área do assentamento, foram utilizados dados coletados do Posto Tauá, localizado no próprio município. Analisando os totais pluviométricos da série histórica entre 1984 e 2014, a pluviosidade média gira em torno de 558,62 mm.

Pode-se observar na figura 03 que a estação das águas apresenta chuvas de verãooutono, enquanto, no resto do ano, prevalece uma estação seca, com escassas precipitações, corroborando com Alves et. al. (2017). Além dessa distribuição irregular durante o ano, também variam as precipitações de um ano para outro, ocasionando secas ou cheias (Figura 04). 
Figura 02

Temperatura média de Tauá.

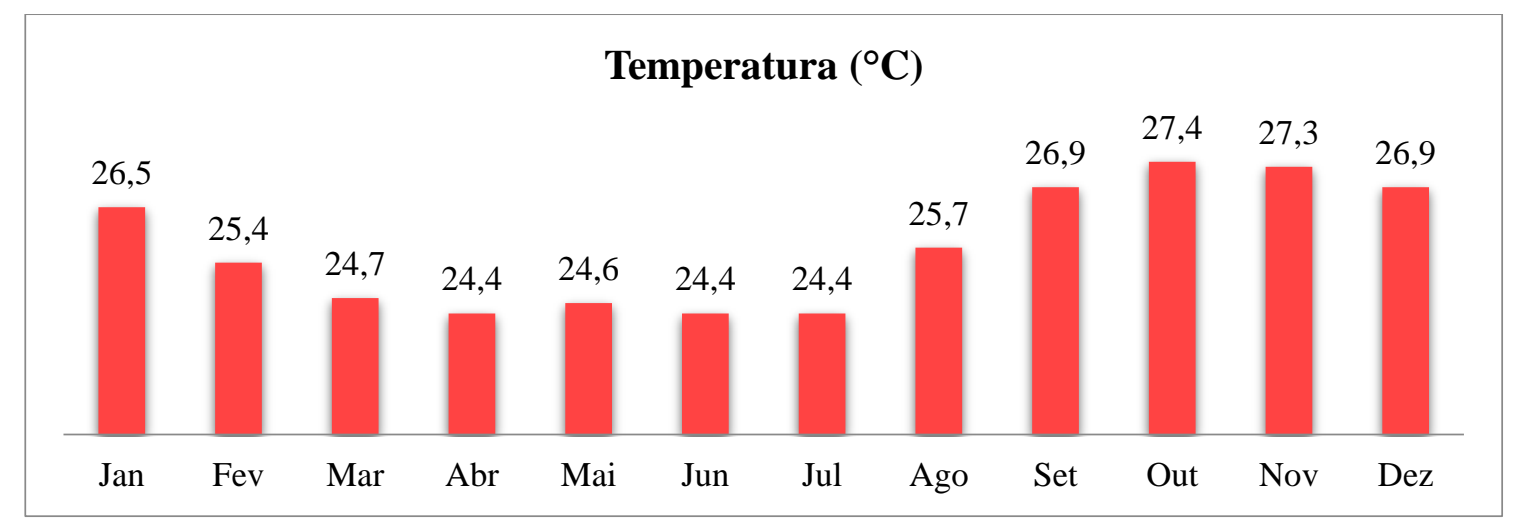

Fonte: Oliveira Neto, 2016, p. 54.

Figura 03

Distribuição pluviométrica média.

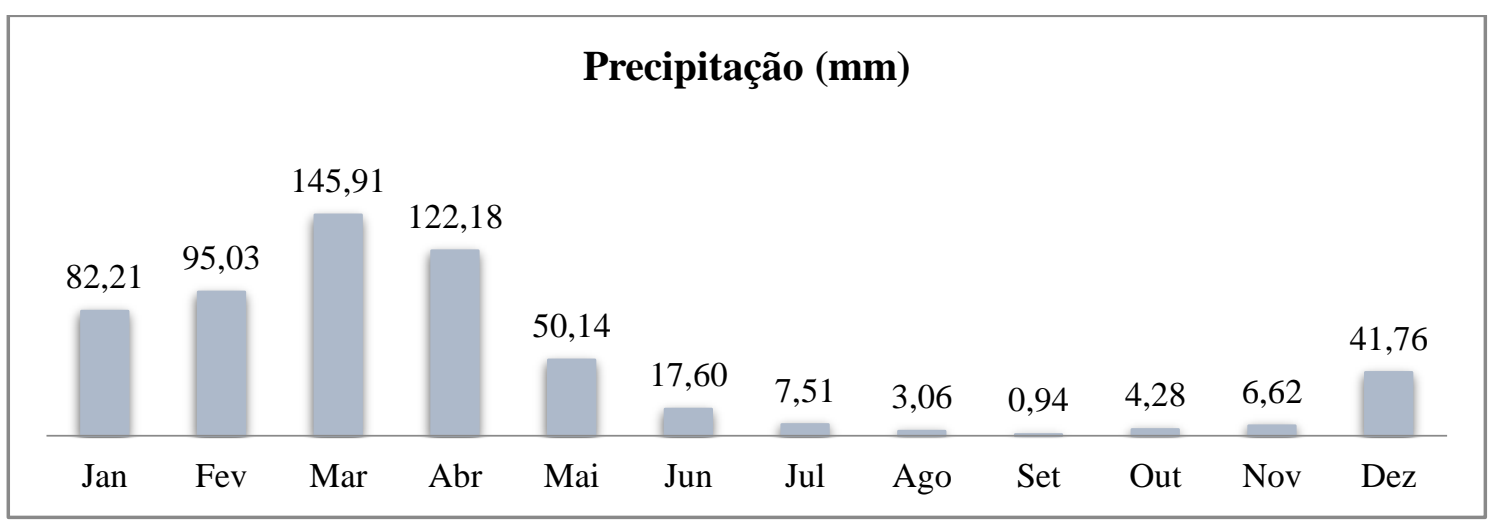

Fonte: Oliveira Neto, 2016, p. 52.

Figura 04

Série histórica pluviométrica.

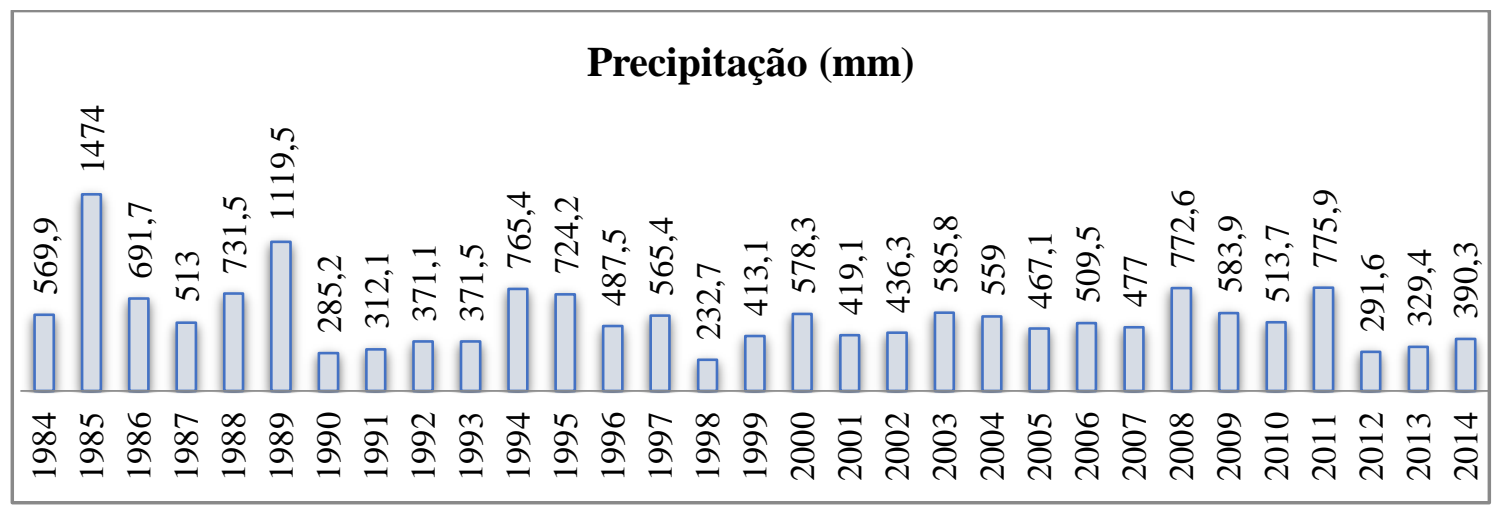

Fonte: Oliveira Neto, 2016, p. 54.

Segundo os resultados obtidos através do NDVI e verificados em campo, para o ano de 
2014, pôde-se observar os níveis de conservação e de degradação da vegetação no assentamento, visualizando três padrões fisionômicos de Caatinga: Caatinga Arbustiva-Arbórea Moderadamente Conservada, Caatinga Arbustiva-Arbórea Degradada e Caatinga Arbustiva Degradada. Com o tratamento da imagem, foi possível observar que a vegetação mais conservada se localiza na parte leste, onde se encontra a Reserva Legal.

Assim como Alves et al. (2020), o modelado do relevo do território do assenamento Angicos II, aliado as informações obtidas com os levantamentos feitos sobre as condições ambientais, permitiu identificar três sistemas ambientais: o Maciço Residual, a Depressão Sertaneja Parcialmente Dissecada e a Depressão Sertaneja Aplainada. A distribuição espacial dos sistemas ambientais pode ser vista na Figura 05, sendo detalhada a seguir. Reforçando Shimbo (2006), o mapeamento dos sistemas ambientais contribui com informações sobre suas limitações e potencialidades, visando direcionar o uso e ocupação em relação à capacidade de suporte de cada unidade ambiental.

Figura 05

Mapa dos Sistemas Ambientais do Assentamento Angicos II (Tauá/CE).

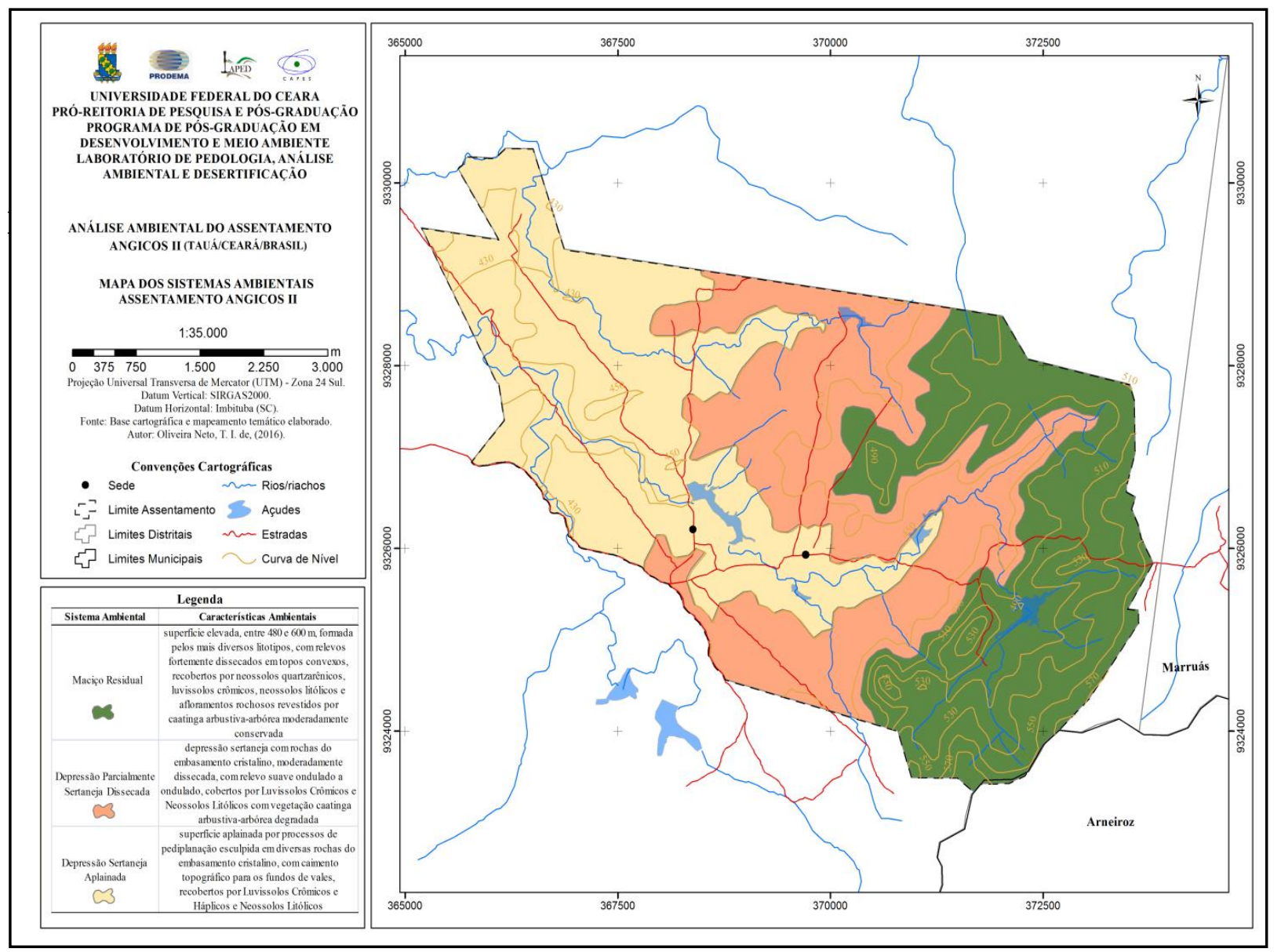

O Maciço Residual apresenta uma área total de pouco mais de 998 ha, o que representa 

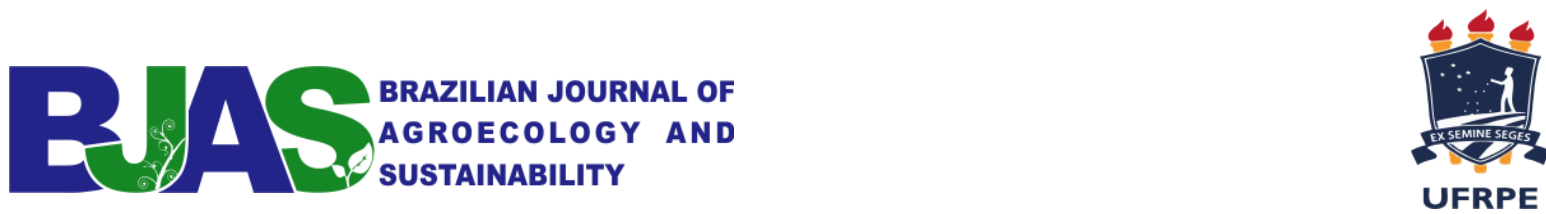

$31 \%$ das terras do assentamento, situado a extremo leste. Este sistema constitui-se de litotipos variados do embasamento cristalino, preponderando os anfibolitos e migmatitos (Figura 06), que justificam os altos por serem mais resistentes à erosão. Apresenta uma superfície elevada entre 480 a $600 \mathrm{~m}$, com relevos ondulado e forte ondulado, fortemente dissecados em formas de topos convexos, cortada por interflúvios dotados de fortes declives, acima de $20 \%$, e medianamente profundos, exibindo feições em formas de cristas residuais e inselbergues (Figura 07).

Figura 06

Afloramento rochoso no Maciço Residual.

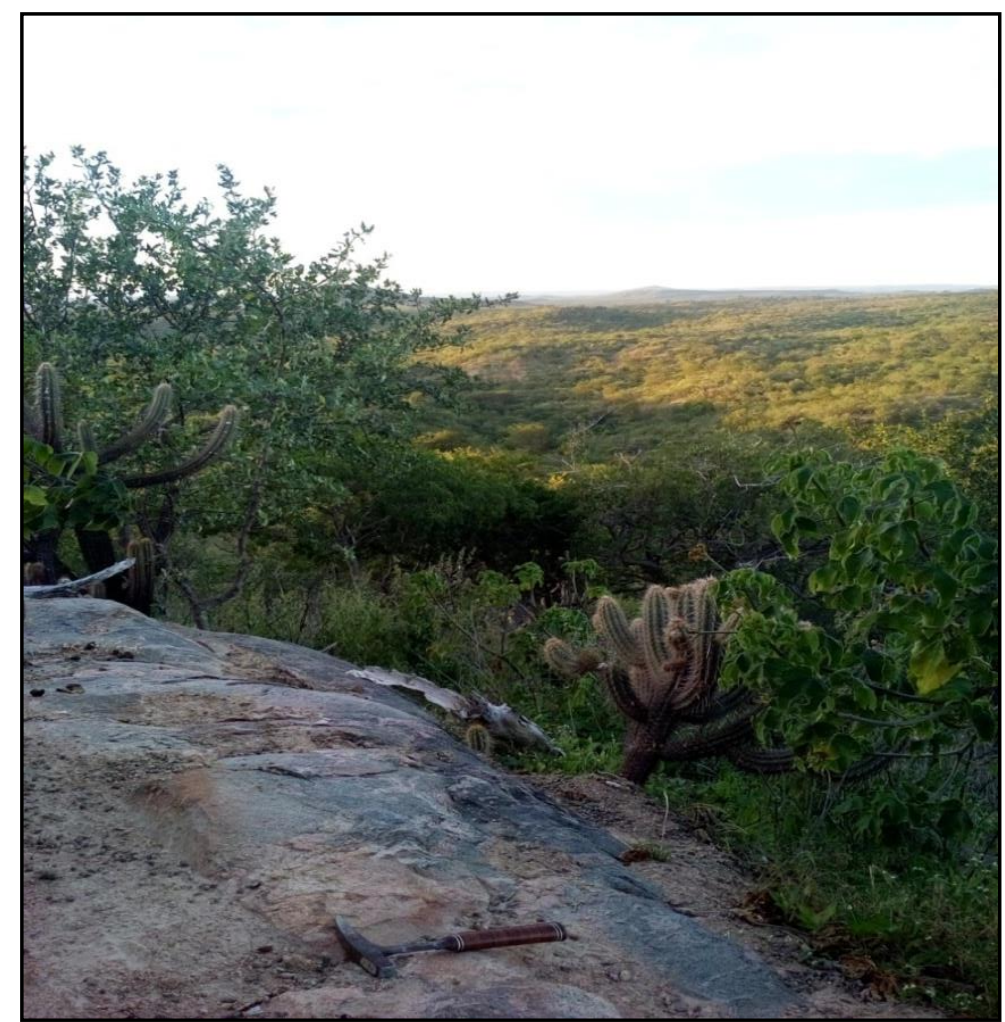

Fonte: Oliveira Neto, 2016, p. 81. 
Figura 07

Vista panorâmica do Maciço Residual.

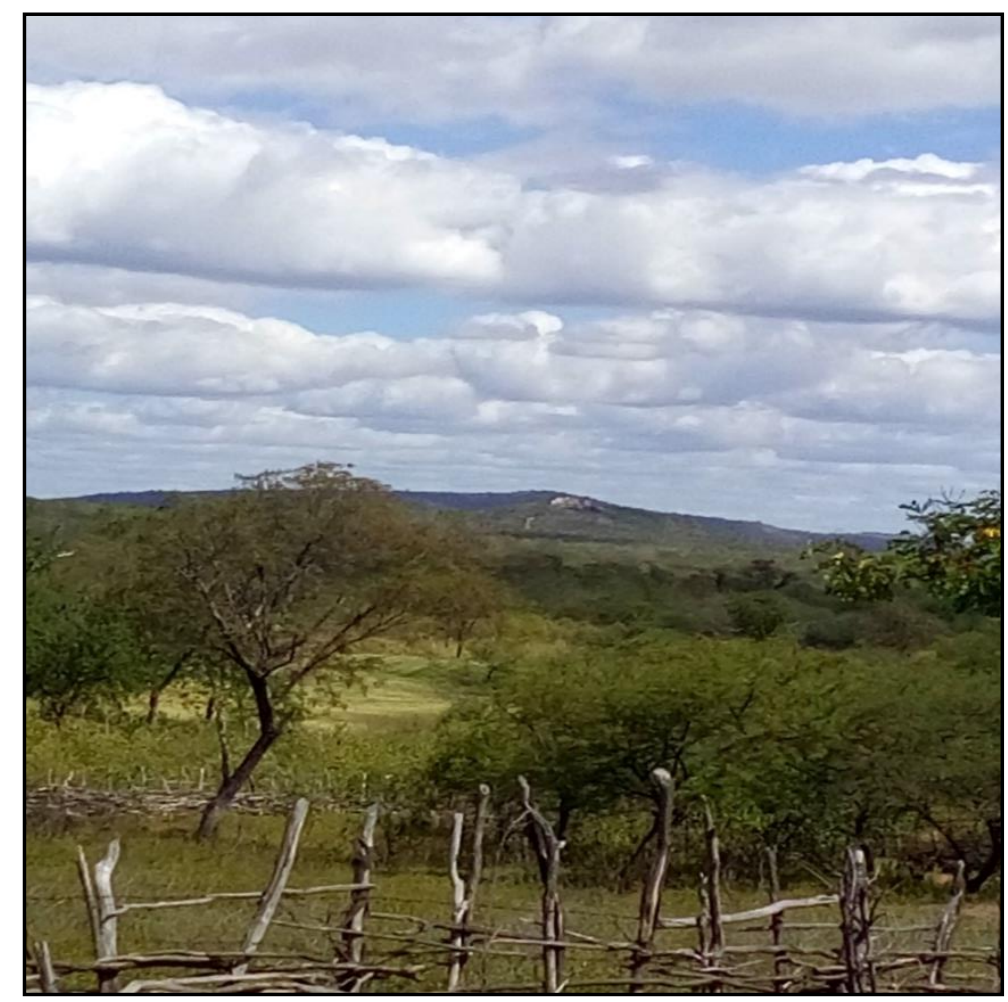

Fonte: Oliveira Neto, 2016, p. 82.

Desta unidade, nascem os principais riachos ou rios efêmeros do assentamento. Os solos encontrados são, principalmente, Neossolos Quarzarênicos, Luvissolos Crômicos, Neossolos Litólicos e afloramentos rochosos, revestidos por uma caatinga arbustiva-arbórea moderadamente conservada.

Fagundes e Gastal (2008) realizaram o diagnóstico ambiental num assentamento rural e verificaram que não havia nenhuma Reserva Legal (RL). Contudo, no Assentamento Angicos II, este sistema ambiental compreende as terras da RL, sendo o menos utilizado por ter parte de sua terra protegida por lei. Entretanto, observou-se que parte deste sistema ambiental não estão protegidas por lei, destaca-se sua utilização pelo extrativismo, com a retirada de lenha e a pecuária extensiva.

No que se refere às potencialidades, destacam-se a boa fertilidade dos solos e o extrativismo. Porém, as terras que compreendem este sistema ambiental apresentam inúmeras limitações, dentre elas pode-se destacar a suscetibilidade à erosão e a dificuldade de manejo decorrente do declive acentuado, limitações quanto aos solos, pela textura arenosa e deficiência de água.

Souza (2000) ressalta que estes ambientes são caracterizados por serem fortemente 

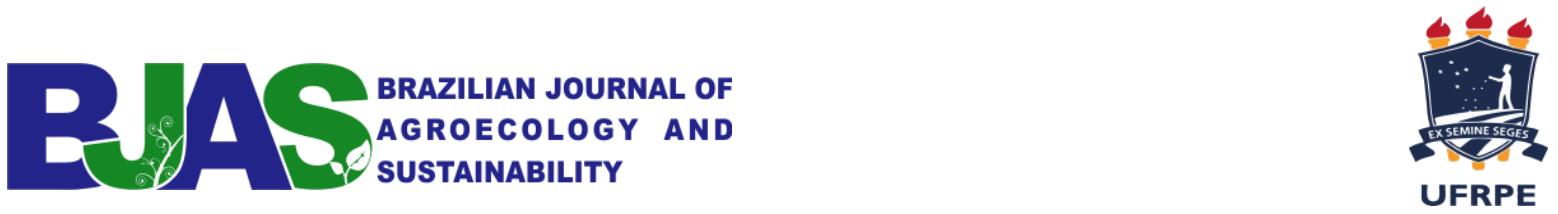

instáveis e com alta vulnerabilidade à ocupação. Deste modo, verifica-se que apresentam ambientes de transição com tendência à estabilidade, onde predominam os processos pedogenéticos. Neste caso, este sistema ambiental apresenta sustentabilidade alta, possuindo boas capacidades produtivas dos recursos naturais se manejados adequadamente. Entretanto, nestas terras, não é aconselhável qualquer tipo de atividade. Recomenda-se serem reservadas para a proteção da flora e da fauna silvestres, visando à manutenção funcional deste sistema ambiental.

\section{Depressão Sertaneja Parcialmente Dissecada}

Este sistema ambiental ocupa uma área de aproximadamente 1.160 ha, cerca de $37 \%$, sendo o maior sistema ambiental do assentamento. Ocupa uma faixa de transição entre os demais sistemas ambientais, com níveis altimétricos variando entre 450 e 480 metros. Este sistema apresenta litotipos variados, como os ortognaisses, anfibolitos e migmatitos. A configuração estrutural, associada a diversos falhamentos e fraturas, expõe um relevo suave ondulado a ondulado, cortado por interflúvios, dotado de declives entre $10 \%$ e $20 \%$, onde predominam as rampas de pedimentação que convergem para os fundos de vales. (Figura 08).

De maneira geral, a superfície é moderadamente dissecada, com aparecimento de sulcos de erosão e erosão laminar. O padrão de drenagem é caracterizado por ser dendrítico, com rios intermitentes sazonais. Sofre os mesmos efeitos decorrentes da expansão e da contração térmica do Maciço Residual, além da pressão e do alívio favorecidos pelos processos meteóricos e biológicos. Os solos encontrados são, sobretudo, Luvissolos Crômicos, Neossolos Litólicos e afloramentos rochosos, revestidos por uma caatinga arbustiva-arbórea degradada, evidenciados pelo desmatamento que se instala com maior intensidade para a produção de lenha.

Esta unidade ambiental já está bastante descaracterizada, apresentando intensa utilização pelos assentados, principalmente, pela agricultura e pela pecuária (Figura 09). No que tange às potencialidades, destacam-se a boa fertilidade dos solos e o extrativismo. Mas as terras deste sistema ambiental também apresentam algumas limitações, como a suscetibilidade à erosão, solos rasos e pedregosos, o que dificulta o manejo, e deficiência de água. 

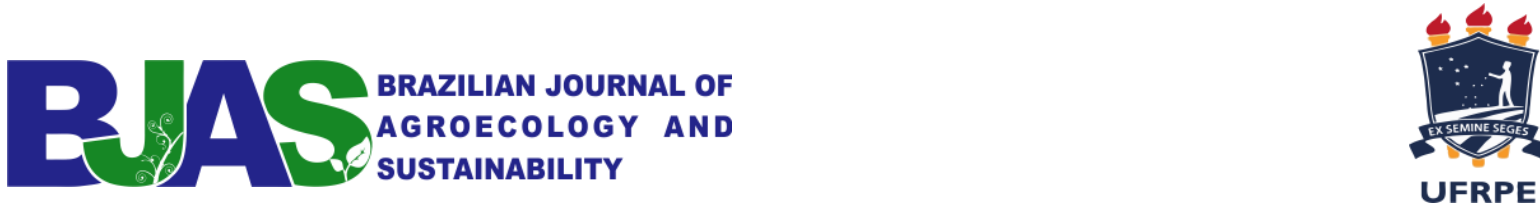

Figura 08

Depressão parcialmente dissecada com ocorrência de pedregulhos e afloramentos rochosos.

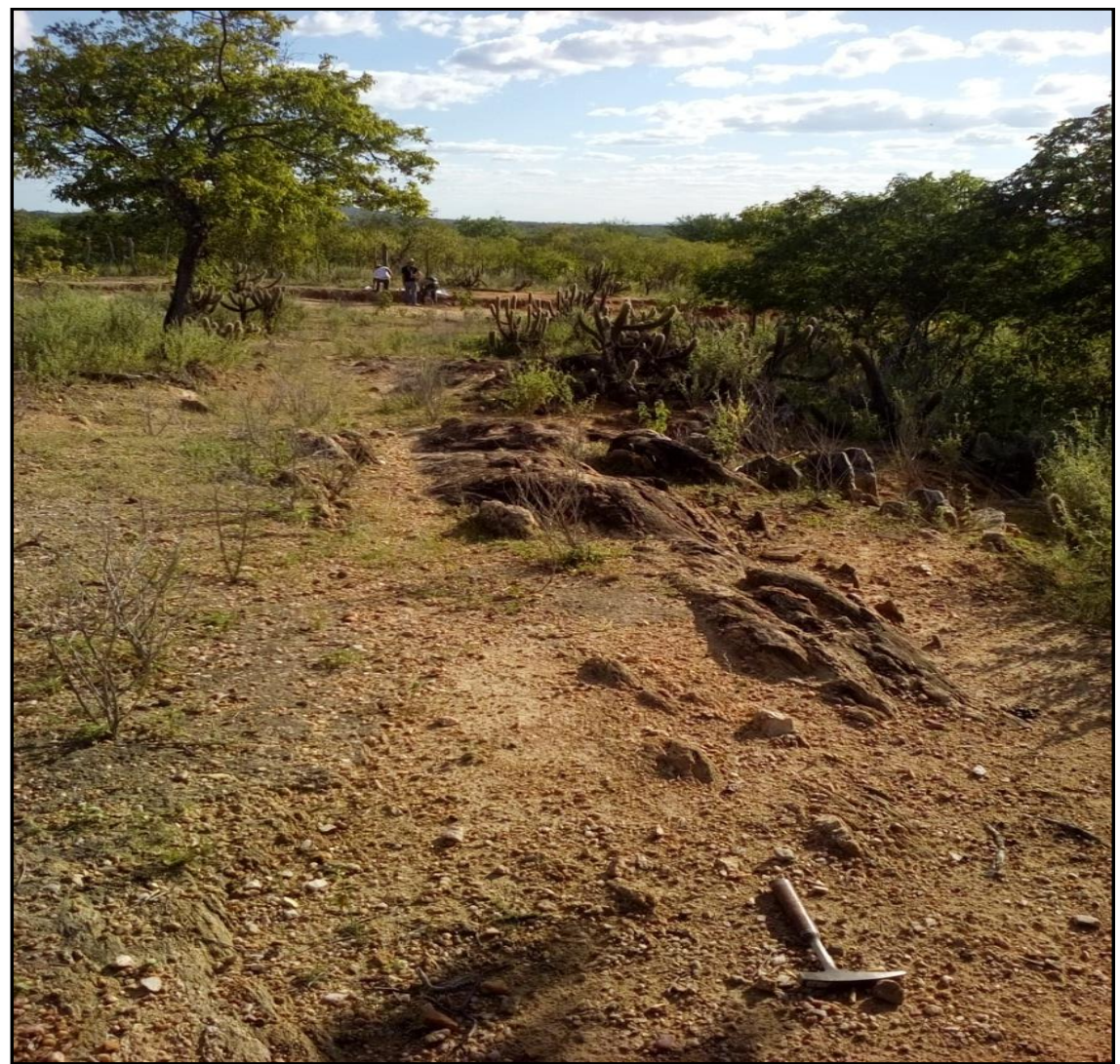

Fonte: Oliveira Neto, 2016, p. 84.

Figura 09

Área de cultivo na Depressão Moderadamente Dissecada.

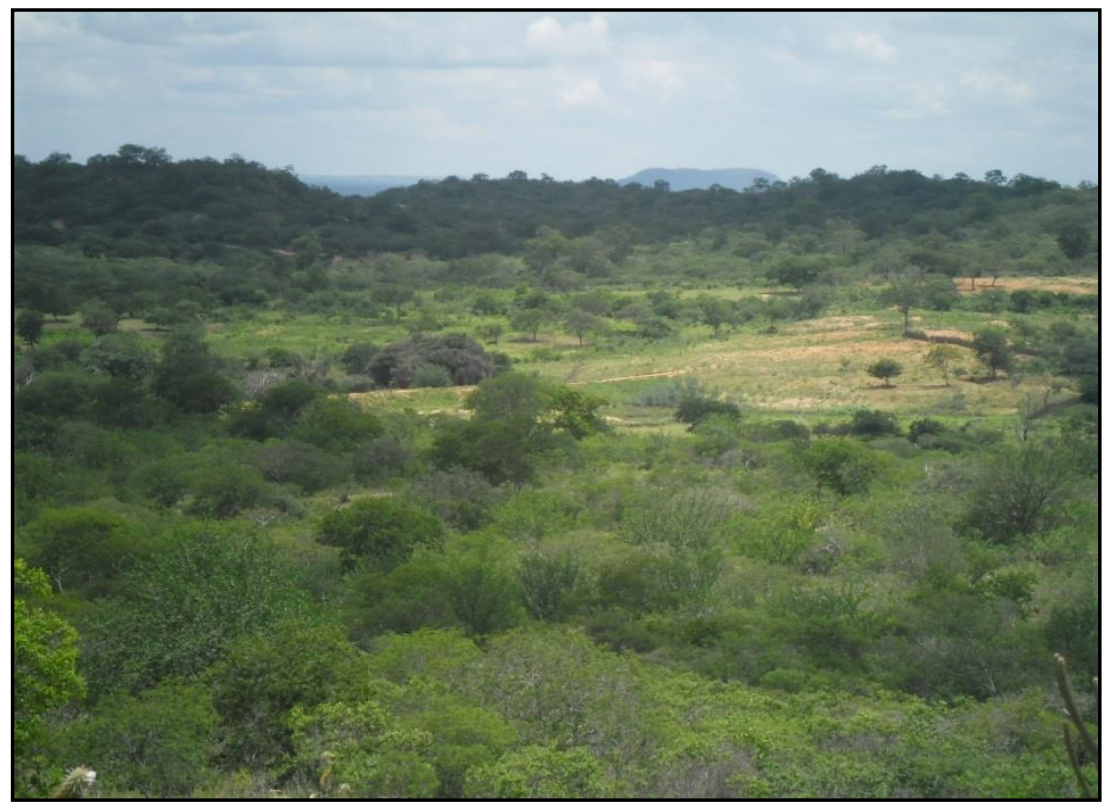

Fonte: Oliveira Neto, 2016, p. 85. 

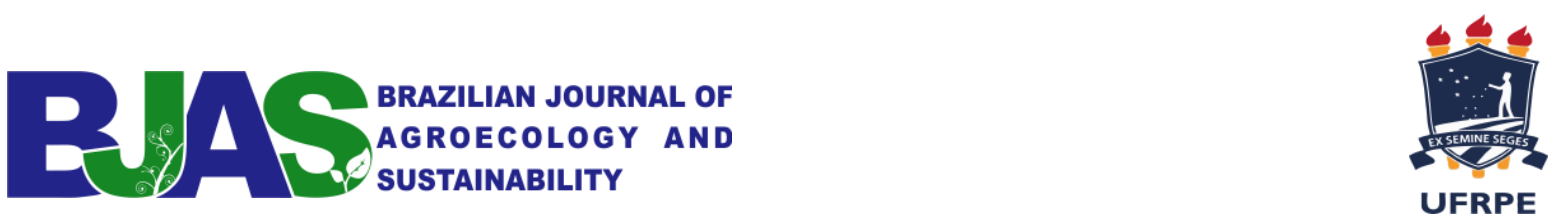

Desta maneira, verifica-se que a Depressão Sertaneja Moderadamente Dissecada apresenta ambiente de transição com tendência à instabilidade, predominando os processos morfogenéticos e modificando as feições do relevo. Neste caso, este sistema ambiental apresenta sustentabilidade moderada, pois manifesta problemas quanto à declividade, que é um fator importante de vulnerabilidade, tornando-se mais suscetível à erosão (Medeiros et al., 2014).

Assim, nestas terras, não é aconselhável a ocupação com lavouras intensas. Recomendase o uso para pastagens, em manejo agrossilvipastoril ou reflorestamento, visando manter a vegetação a fim de evitar processos de erosão, pois, se não manejadas adequadamente, correm risco de ampliação dos processos de degradação ambiental. Pois, Leite (2018) analisando a vulnerabilidade ambiental de um assentamento, observou que a supressão da vegetação de maior densidade indicou aumento na vulnerabilidade, sobretudo, com impactos relacionados a implantação do assentamento rural.

\section{Depressão Sertaneja Aplainada}

A Depressão Sertaneja Aplainada compreende uma área de mais de 1.000 ha, representando $32 \%$ do assentamento. É composta por uma grande diversidade de rochas, como rochas graníticas, anfibolitos, migmatitos, dentre outras rochas do embasamento cristalino. Penteado (1980) afirma que estas porções da crosta correspondentes ao antigo assoalho de velhos dobramentos foram várias vezes soerguidas. Souza (2000) corrobora salientando que estes eventos traduzem a relação da morfologia com os fatores litológicos e as evidências de flutuações climáticas cenozoicas. Apresenta uma superfície aplainada entre os níveis de 400 e $450 \mathrm{~m}$, com relevos planos à suave ondulado, truncado pela morfogênese mecânica, com predomínio de rampas de pedimentações que convergem para os fundos dos vales (Figura 10). Para Souza (1988), a morfologia da depressão sertaneja expõe superfícies de aplainamento, onde o trabalho da erosão truncou os mais diversos tipos de rochas. 
Figura 10

Rampa de pediplanação próximo ao riacho Jurema.

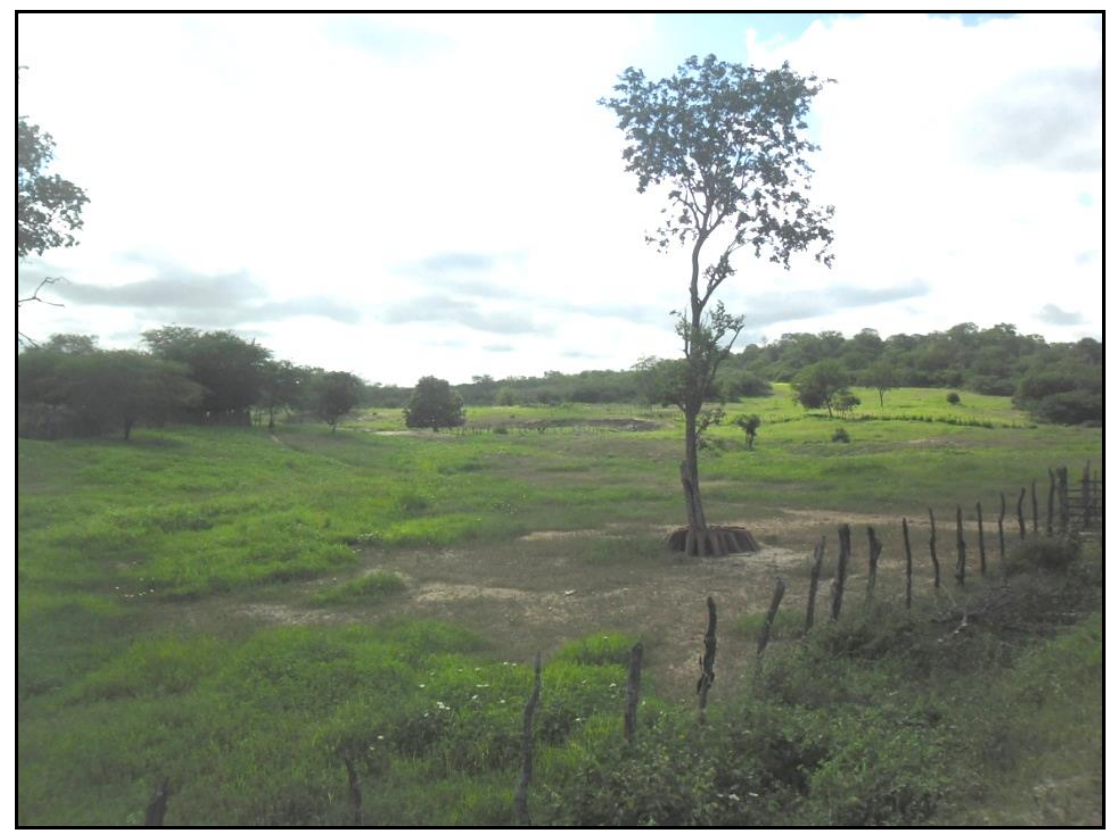

Fonte: Oliveira Neto, 2016, p. 87.

Esta superfície foi desenvolvida a partir do processo de pediplanação, em que os processos de erosão areolar são bem mais ativos do que os processos de erosão linear, que resultam na construção de superfícies aplainadas (Penteado, 1980). O entalhe da erosão linear engendrou um padrão de drenagrem dos rios dendríticos, com regime intermitente sazonal. Os solos encontrados são Luvissolos Háplicos e Crômicos, Neossolos Litólicos, revestidos pela caatinga arbustiva bastante degradada, pois este sistema é o mais utilizado pelos assentados. Os tipos de uso verificados nesta unidade são a agricultura (Figura 11) e a pecuária, além do extrativismo. 
Figura 11

Cultivo de palma (Opuntia sp.) na depressão sertaneja.

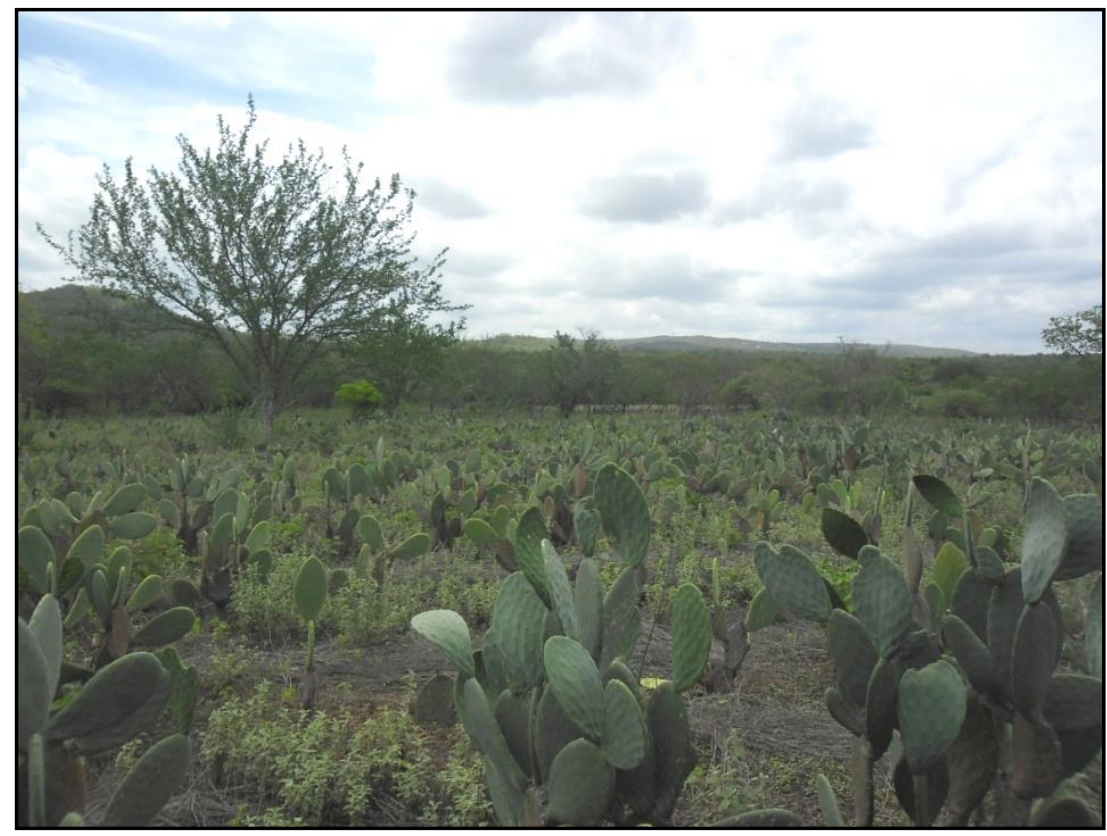

Fonte: Oliveira Neto, 2016, p. 87.

Dentre as potencialidades da depressão, destacam-se os recursos hídricos de superfície - por meio da açudagem - o relevo favorável ao uso da agropecuária, mediante a boa fertilidade dos solos, ressaltando que o mesmo ocorra com um manejo adequado. Não obstante, as terras deste sistema ambiental apresentam algumas limitações, dentre elas destacam-se: irregularidades pluviométricas, presença de solos pouco profundos e baixa biodiversidade em função da gradação ambiental.

Apresenta-se como ambiente de transição com tendência à instabilidade, onde verificaram-se ações de cunho degradacionais. Neste caso, este sistema ambiental apresenta sustentabilidade baixa, manifestando-se problemas quanto à capacidade produtiva dos seus recursos naturais. Estas terras são próprias para diversos usos, pois apresentam limitações pequenas, podendo ser efetivamente suplantadas com técnicas de manejo e conservação dos solos adequadas ao sistema ambiental.

Para Carvalho et al. (2017), as práticas de manejo de solo diagnosticadas refletem a realidade de diversas propriedades rurais do semiárido nordestino. Assim, o uso inadequado deste sistema ambiental ao longo dos anos pode gerar impactos ambientais que comprometam o equilíbrio natural do baixio, levando a condições extremas de desertificação. 


\section{CONCLUSÕES}

Os resultados demonstram que a análise ambiental contribuiu significativamente na interpretação dos dados para a elaboração dos PDA.

A análise geossistêmica, por meio da integração, proporcionou perceber as condições ambientais, além de apreender o comportamento dos agentes que compõem o objeto estudado e a sustentabilidade dos sistemas ambientais.

Os estudos setoriais são essenciais para a compreensão da dinâmica do assentamento. Diante disto, é evidente que a análise ambiental é uma ferramenta que subsidia o planejamento ambiental.

Apresentou-se aqui uma contribuição para que os assentados possam utilizar as melhores práticas, visando à sustentabilidade ambiental dos seus recursos naturais.

Por fim, percebeu-se pouco estímulo à aplicação da análise ambiental, baseada no conceito de geossistema, nos diagnósticos do meio físico para implementação dos PDA.

\section{REFERÊNCIAS}

Araújo, C. E. G. de, \& Naleto, J. L. C. (2014). Mapa Geológico Folha Mombaça SB.24-V-D$V$. Fortaleza: CPRM.

Araújo, A. et al. (2018). Regularização fundiária e qualidade de vida dos assentados no projeto estadual de assentamento agroextrativista Gleba Majari I - Porto de Moz-PA. Revista de Geografia e Ordenamento do Território (GOT), (14), 47-70.

Alves, C. M. dos, \& Feitosa, A. V. M. (2002). Plano de Desenvolvimento do Assentamento Angicos II. Tauá: Secretaria de Assistência Social/Prefeitura Municipal de Tauá.

Alves, J. M. B. et al. (2017). Eventos Extremos Diários de Chuva no Nordeste do Brasil e Características Atmosféricas. Revista Brasileira de Meteorologia, 32(2), 227-233.

Alves, G. B. M. et al. (2020). Análise Ambiental do Desmatamento em Área de Assentamento Rural no Cerrado (Mato Grosso, Brasil). Terra Plural, 17, 1-13.

Bertrand, G. (2004). Paisagem e Geografia Física Global: esboço metodológico. Revista RA 'E $G A,(8), 141-152$.

Brasil. (1993). Lei $\mathrm{N}^{\circ}$ 8.629, de 25 de fevereiro de 1993- Dispõe sobre a regulamentação dos dispositivos constitucionais relativos à reforma agrária, previstos no Capítulo III, Título VII, da Constituição Federal. Diário Oficial República do Brasil. Brasília, DF. Recuperado de http://www.planalto.gov.br/ccivil_03/leis/18629.htm. 

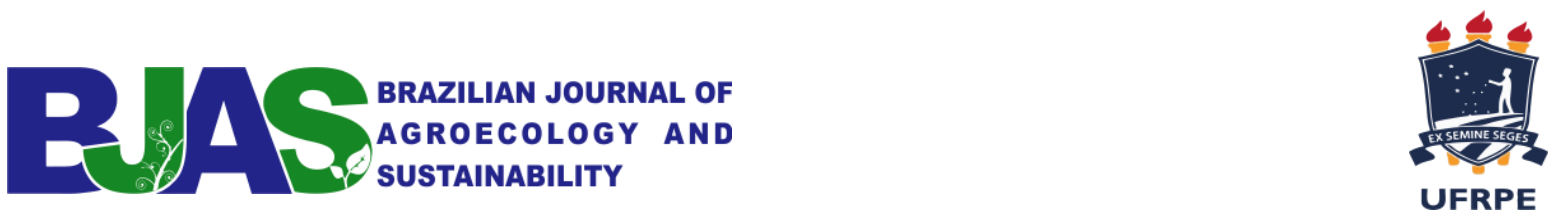

Brasil. Conselho Nacional de Meio Ambiente. (2006). Resolução No 387, de 27 de dezembro de 2006 - Estabelece Procedimentos para o Licenciamento Ambiental de Projetos de Assentamentos de Reforma Agrária e dá outras Providências. Diário Oficial República do Brasil, Brasília, DF. Recuperado de http://www2.mma.gov.br/port/conama/res/res06/res38706.pdf

Brasil. (2012). Lei No 12.651, de 25 de maio de 2012 - Dispõe sobre a proteção da vegetação nativa; altera as Leis $\mathrm{n}^{\circ} \mathrm{s} 6.938$, de 31 de agosto de 1981, 9.393, de 19 de dezembro de 1996, e 11.428, de 22 de dezembro de 2006; revoga as Leis $\mathrm{n}^{\circ} \mathrm{s} 4.771$, de 15 de setembro de 1965, e 7.754, de 14 de abril de 1989, e a Medida Provisória no 2.166-67, de 24 de agosto de 2001; e dá outras providências. Diário Oficial República do Brasil, Brasília, DF. Recuperado de http://www.planalto.gov.br/ccivil_03/_ato20112014/2012/lei/112651.htm.

Cavalcanti, J. A. D. (2011). Mapa Geológico Folha Várzea do Boi SB.24-V-D-IV. Fortaleza: CPRM.

Ceará. Fundação Instituto de Planejamento do Ceará. (1997). Atlas do Ceará. Fortaleza: Edições Iplance.

Ceará. Fundação Cearense de Meteorologia e Recursos Hídricos. (2009). Compartimentação Geoambiental do Estado do Ceará. Fortaleza: Funceme.

Costa, G. (2007). Celina: estimativa de temperaturas para o Estado do Ceará. Versão 1.0. UFC: Departamento de Geografia.

Embrapa. (2005). Manual de Descrição e Coleta de Solo no Campo (5a ed.). Viçosa, MG: Sociedade Brasileira de Ciência do Solo.

Fagundes, N. A., \& Gastal Junior, C. V. de. S. (2008). Diagnóstico Ambiental e Delimitação de Áreas de Preservação Permanente em um Assentamento Rural. Acta Sci. Biol. Sci., 30(1), 29-38.

Freitas, H. R. et al. (2018). Sistemas de Avaliação de Terra e Conhecimento Etnopedológicos no Planejamento de Assentamentos Rurais: um estudo de caso nos mares de morro de Minas Gerais. Revista Brasileira de Agroecologia, 13(3), 76-89.

Jacomine, P. K. T. Almeida, J. C., \& Medeiros, L. A. R. (1973). Levantamento ExploratórioReconhecimento de solos do Estado do Ceará. Recife: DNPEA/DRN-SUDENE.

Leite, C. C. (2018). Avaliação da Vulnerabilidade Ambiental em Assentamento Rural do Estado de Alagoas. Dissertação de Mestrado em Recursos Hídricos e Saneamento, Programa de Pós-Graduação em Recursos Hídricos e Saneamento, Centro de Tecnologia, Universidade Federal de Alagoas, Maceió.

Lepsch, I. F. (2011). 19 Lições de Pedologia. São Paulo: Oficina de Textos.

Medeiros, R. B. (2014). Avaliação da Vulnerabilidade Ambiental na Área do Assentamento São Joaquim, Selvíria/MS. Revista Caminhos de Geografia, 15(49), 126-137. 

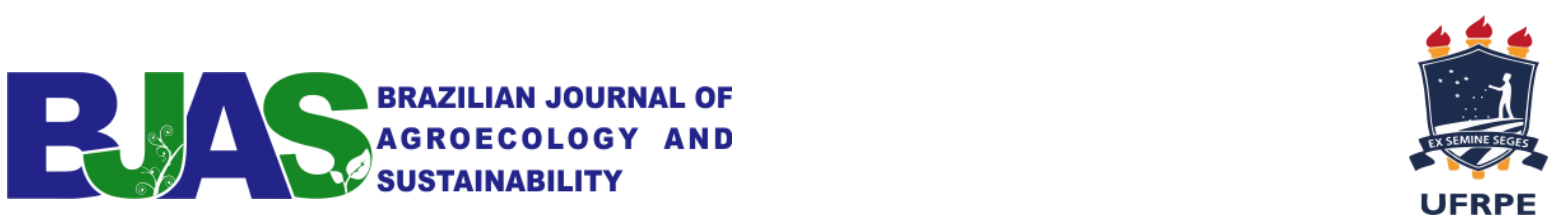

Miranda, R. de S., \& Cunha, L. H. H. (2018). Análise do Processo de Elaboração de Planos de Desenvolvimento de Assentamentos Rurais no Semiárido Nordestino. Revista de Políticas Públicas, 22(1), 395-415.

Odum, E. P., \& Barrett, G. W. (2007). Fundamentos de Ecologia (5a ed.). São Paulo: Thompson Learning.

Oliveira Neto. T. I. de. (2016). Análise Ambiental do Assentamento Angicos II (Tauá/Ceará). Dissertação de Mestrado em Desenvolvimento e Meio Ambiente, Programa de PósGraduação em Desenvolvimento e Meio Ambiente, Centro de Ciências, Universidade Federal do Ceará, Fortaleza.

Penteado, M. M. (1980). Fundamento de Geomorfologia (3a ed.). Rio de Janeiro: IBGE.

Ponzoni, F. J., Shimabukuro, Y. E., \& Kuplich, T. M. (2012). Sensoriamento Remoto da Vegetação (2a ed.). São Paulo: Oficina de Textos.

Rosa, R. (2004). Cartografia básica. Uberlândia: Laboratório de Geoprocessamento, Instituto de Geografia (UFU).

Santos, J. G. R., \& Castro, S. S. (2019). Análise da Sustentabilidade de Projetos de Assentamentos Rurais em Goiás. Revista GeoUSP - Espaço e Tempo, 23(2), 394-416.

Silva, C. C. (2016). Composição de um Plano de Desenvolvimento de Assentamento (PDA): $P A$ "Márcia Cordeiro Leite". Relatório de Estágio Supervisionado, Curso de Gestão do Agronegócio, Faculdade UnB Planaltina (FUP/UNB), Planaltina, 2011.

Souza, M. J. N. de. (1988). Contribuição ao Estudo das Unidades Morfo-Estruturais do Estado do Ceará. Revista de Geologia, 1(1), 73-91.

Souza, M. J. N. de. Bases naturais e esboço do zoneamento geoambiental do Estado do Ceará. In L. C. Lima, J. O. de Morais, \& M. J. N. de Souza. (2000). Compartimentação territorial e gestão regional do Ceará. Fortaleza: FUNECE.

Souza, M. J. N. de, Oliveira, V. P. V. de, \& Granjeiro, C. M. M. Análise Geoambiental. In D. Elias (Org.). (2002). O Novo espaço da produção globalizada: o baixo Jaguaribe. Fortaleza: FUNECE.

Souza, M. J. N. de. Compartimentação geoambiental do Ceará. In J. B. da Silva et. al. (2007). Ceará: um novo olhar geográfico (2a ed.). Fortaleza: Edições Demócrito Rocha.

Souza, M. J. N. de et al. (2009). Diagnóstico geoambiental do Município de Fortaleza: subsídios ao macrozoneamento ambiental e a revisão do plano diretor participativo PDPFor. Fortaleza: Prefeitura Municipal de Fortaleza.

Souza, M. J. N. de, \& Oliveira, V. P. V. de. (2011). Análise Ambiental: uma prática da intedisciplinaridade no ensino e na pesquisa. REDE - Revista Eletrônica do PRODEMA, 7(2), 42-59. 


\section{AGRADECIMENTOS}

Os autores agradecem ao financiamento da pesquisa "Análise Ambiental do Assentamento Angicos II (Tauá/Ceará), desenvolvida junto ao PRODEMA, devido a manutenção da bolsa de auxílio pelo Programa de Demanda Social da CAPES (Coordenação de Aperfeiçoamento de Pessoal de Nível Superior), entre 2014 e 2016; e, atualmente, ao Programa CAPES/FUNCAP (Fundação Cearense de Apoio ao Desenvolvimento Científico e Tecnológico) Proc. 88887.165948/2018-00: Apoio às Estratégias de Cooperação Científica do Programa de Pós-Graduação em Geografia - UFC. 